\title{
O MOVIMENTO POLÍTICO INDÍGENA EM RORAIMA: identidades indígenas e nacionais na fronteira Brasil-Guiana ${ }^{1}$
}

\author{
Stephen Grant Baines*
}

\begin{abstract}
O trabalho aborda o movimento político indígena que se consolidou a partir da década de 70 do século XX, no Estado de Roraima, com o fortalecimento de identidades indígenas, focalizando, sobretudo, os Makuxi e os Wapichana. Analisa-se a interface dessas identidades com as identidades nacionais de brasileiro e guianense na fronteira internacional, que se consolidaram a partir da definição dessa fronteira em 1904. Examina-se como se sobrepõem essas identidades, e como se convivem simultaneamente como identidades contextualizadas entre os povos indígenas que habitam essa região desde muito antes da imposição da fronteira internacional. PALAVRAS-CHAVE: movimento indígena, Makuxi, Wapichana, identidades nacionais e étnicas, fronteira.
\end{abstract}

\section{INTRODUÇÃO}

Neste trabalho, focalizamos o movimento político indígena em Roraima com base em uma pesquisa iniciada em 2001 junto aos povos indígenas Makuxi e Wapichana, ao longo da fronteira internacional entre Roraima, Brasil e Região 8 e Região 9 (a antiga região conhecida como Rupununi) da República da Guiana. Até o início da década de 70 do século XX, essas populações indígenas, após mais de duzentos anos de contato interétnico com segmentos das sociedades nacionais brasileira e guianense, e décadas de subordinação a fazendeiros e garimpeiros que invadiam suas terras, eram vistas pela população regional como populações

* Professor associado do Departamento de Antropologia (DAN) da Universidade de Brasília (UnB). Pesquisador 1 do CNPq.

UnB. Campus Universitário Darcy Ribeiro. Cep: 70904970. Caixa-Postal: 04495. Brasília - Distrito Federal Brasil. stephen@unb.br

${ }^{1}$ Uma versão deste trabalho foi apresentada no GT 11 Estudos rurais e etnologia indígena: diálogos e intersecções -, coordenado pelas professoras Emília Pietrafesa de Godo (Universidade Estadual de Campinas) e Maria Rosário Carvalho (Universidade Federal da Bahia), no $35^{\circ}$ Encontro Anual da Associação Nacional de Pós-Graduação e Pesquisa em Ciências Sociais (ANPOCS) em Caxambu, outubro de 2011 rurais, índios camponeses, ou "cabocos". Nos últimos quarenta anos, o protagonismo indígena inverteu parcialmente essa situação.

A ocupação colonial portuguesa dessa região teve início na década de 70 do século XVIII, na forma de uma ocupação estratégico-militar. Os portugueses preocuparam-se em assegurar a posse dessa área limítrofe e evitar possíveis invasões por espanhóis e holandeses vindos do Norte (Farage, 1991). O processo de aldeamento de indígenas pelos portugueses em "aldeamentos [...] compostos multietnicamente" (1991, p.125), na segunda metade do século XVIII, é descrito por Farage, que usa fontes históricas para revelar que houve uma série de revoltas nas últimas décadas, resposta à "superexploração do trabalho dos índios aldeados" (p.131).

Farage (1991, p.131) também relata fugas maciças que se alastraram nos referidos aldeamentos "na razão direta da violência utilizada pelos portugueses para reprimi-los". Para essa mesma autora, "O recrutamento de mão-de-obra, tal como previa o parágrafo 62 do Diretório, era feito através de 'principais' índios, que deveriam 
apresentar a seu tempo os trabalhadores requisitados pelos portugueses.” (p.131).

O parecer do governador da Capitania de São José do Rio Negro, Manuel da Gama Lobo D’Almada, “junto a Lisboa era pela declaração de guerra aos insurrectos, que deveriam ser capturados e reduzidos à obediência.” (Farage, 1991, p.134). Diante do levante indígena de 1790, o mesmo governador, que antes havia defendido preceitos de coloração humanista no trato com os indígenas, foi “a primeira voz a lembrar a necessidade da 'demonstração de castigo com os Delinquentes”' (p.165).

Na segunda metade do século XIX, Henri Coudreau descreve os Wapichana como "índios vestidos" e observou que trabalhavam ocasionalmente para os brancos (Coudreau, 1887, IX, p.265 apud Farage, 1997, p.33). A partir da sua reclassificação como "índio vestido”, essa população indígena veio a ser invisibilizada etnicamente na categoria de "trabalhadores" (1997, p.41). Em 1889, Stradelli descreve os Wapichana como "Trabalhadores e dóceis, prestam-se de boa vontade ao serviço dos brancos” (apud Farage, 1997, p.41). Observa Farage que, na década de 10 do século XX, o etnógrafo Koch-Grünberg "passava ao largo do território Wapishana, em busca dos povos Carib ao norte, desde que supunha, como H. Coudreau, que, entre os primeiros, nada haveria que valesse constar de uma coleção etnográfica.” (1997, p.41). No final do século XIX e no início do século XX, os Wapichana já foram vistos como populações camponesas, mesmo por etnógrafos da época.

Depois dos conflitos entre os governos do Brasil e da Grã-Bretanha na então colônia da Guiana Inglesa, sobre a definição da fronteira no final do século XIX e no início do século XX (Rivière, 1995), as terras dos povos indígenas que habitavam essa região foram divididas pela linha fronteiriça traçada entre o Brasil e a Guiana em 1904. No lado brasileiro dessa fronteira, foram estabelecidas duas agências indigenistas no início do século XX: o Serviço de Proteção aos Índios (SPI), sediado na fazenda São Marcos, e a missão evangelizadora beneditina no alto rio Surumu, ambos substituídos, respectivamente, pela Fundação Nacional do Índio (FUNAI) e pela Ordem da Consolata (Santilli, 2001, p.39-40). Apesar de se valerem de procedimentos clientelistas semelhantes às mediações entre regionais e índios ao longo das décadas anteriores, visavam a outros fins. Para Santilli (2001), nesse período, buscou-se transformar os índios em trabalhadores nacionais. Usando-se o que ele chama um “padrão clientelista”, investiu-se "na construção de intermediários políticos, na figura de 'tuxauas' ou líderes de aldeia, que as agências indigenistas buscavam legitimar e consolidar." (2001, p.40).

Ramos, ao ressaltar a enorme mudança que ocorreu em um período de quarenta anos, em decorrência da consolidação do movimento político indígena e da profissionalização de lideranças indígenas, assim descreve os Makuxi na década de 60 do século XX, na capital de Roraima:

Eram humildes varredores das ruas de Boa Vista que mal ousavam levantar os olhos do chão e pareciam querer fazer-se invisíveis para aquele mundo hostil, que os rechaçava ostensivamente. Viviam então o lado mais sombrio da fricção interétnica, relegados à absoluta marginalidade social, cultural e econômica. Quarenta anos depois, eles eram os protagonistas de uma das mais célebres batalhas judiciais dos tempos modernos ao defender, em igualdade de condições, os seus direitos territoriais. Os esforços dos advogados dos Macuxi foram cruciais para que os indígenas da Raposa-Serra do Sol saíssem vitoriosos na decisão do Supremo Tribunal Federal que afastou invasores arrogantes e belicosos (Miras et al., 2009). A educação formal transformou a invisibilidade macuxi numa demonstração exemplar de agencialidade política (Ramos, 2011, p.20).

O processo de protagonismo indígena em Roraima foi construído a partir de uma colaboração entre agências indigenistas e lideranças indígenas. Tanto os religiosos como os agentes do Serviço de Proteção aos Índios (SPI) e, posteriormente, da Fundação Nacional do Índio (FUNAI) procuravam minar os vínculos clientelistas que ligavam os índios aos regionais (Santilli, 2001, p.41). A partir de 1975, a Diocese 
de Roraima passou a patrocinar reuniões anuais chamadas "assembleias de tuxauas". Criou-se um "projeto de cantinas" e, na década de 80, a Diocese de Roraima programou o "projeto do gado", com o objetivo de promover a ocupação do lavrado, transformando os índios em pecuaristas. Dessas iniciativas resultaram, em 1984, os Conselhos Regionais e, posteriormente, uma coordenação em Boa Vista, que veio a ser o Conselho Indígena de Roraima (CIR). Santilli assinala que, "descolando-se do plano aldeão, o Conselho Indígena erigiu-se verticalmente, privilegiando a hierarquia e a representação política em moldes partidários". Ressalta também:

... o suporte material para a organização do Conselho Indígena - e isso foi se tornando mais patente a cada fracasso dos 'projetos comunitários' concebidos pelas agências indigenistas - depende visceralmente de recursos externos, sejam eles injetados por missionários católicos, sejam provenientes de órgãos oficiais como a Funai, sejam mesmo de cooperação internacional (Santilli, 2001, p.44).

Focalizamos o impacto das políticas indigenistas nessa região de fronteira e as estratégias indígenas para afirmar seus direitos perante os Estados nacionais, processo de protagonismo indígena em que essas populações têmse afastado da identidade de "caboco" camponês e se afirmado como povos indígenas.

\section{ORIENTAÇÕES TEÓRICAS}

Partimos do estudo sobre nacionalidade e etnicidade em áreas de fronteira iniciado no Brasil por Roberto Cardoso de Oliveira (Oliveira; Baines, 2005). Ao se referir aos espaços fronteiriços, ressalta Oliveira:

... quanto à nacionalidade, como uma segunda identidade, é claro que ela será instrumentalizada de conformidade com situações concretas em que os indivíduos ou os grupos estiverem inseridos, como a de procurarem assistência à saúde, à educação dos filhos ou uma eventual proteção junto a forças militares de fronteira: seriam casos típicos de manipulação de identidade junto a repre- sentantes dos respectivos Estados nacionais. (2000, p.17)

Sobre o caso de etnias localizadas em fronteiras entre Estados nacionais, afirma Oliveira:

... não se trata mais de considerá-las em si mesmas, i. é, como tais, mas de inseri-las num outro quadro de referência: o quadro (inter)nacional. A rigor, poder-se-ia dizer que tal quadro teria sua configuração marcada por um processo transnacional, apontando esse termo para o caráter dinâmico das relações sociais vividas pelo contingente populacional localizado na fronteira. [...] Portanto, no caso de uma situação de fronteira, aquilo que surge como um poderoso determinador social, político e cultural - provavelmente mais do que a etnicidade - passa a ser a nacionalidade dos agentes sociais; é quando nacionalidade e etnicidade se interseccionam [...]. E é exatamente esse espaço ocupado pela nacionalidade que tende a se internacionalizar, graças ao processo de transnacionalização que nele tem lugar (2005, p.14-15).

O foco privilegiado de investigação será "não mais o sistema interétnico (como nas teorias [...] da fricção interétnica, que no Brasil surgiu nos anos 1960), mas o sistema inter e transnacional, visto em termos das nacionalidades em conjunção.” (Oliveira, 2005, p.15). Examinaremos os Makuxi e os Wapichana na fronteira Brasil-Guiana, à luz dessas observações de Roberto Cardoso de Oliveira.

POVOS INDÍGENAS NA FRONTEIRA BRASILGUIANA

No caso em discussão, tanto o Brasil quanto a Guiana - embora a segunda seja mais de 39 vezes menor que o Brasil em extensão territorial (Baines, 2004, p.78) -, compartilham o fato de que a população majoritária não indígena concentra-se no litoral, e a população indígena é uma pequena minoria das populações nacionais, concentrada em regiões distantes dos grandes centros urbanos e ao longo das fronteiras internacionais. Na Guiana, colônia holandesa que se tornou colônia inglesa até sua independência em 1966, a história das relações entre os povos indí- 
genas e os poderes coloniais foi marcada por tratados de comércio com os povos indígenas. O governo da Guiana nunca extinguiu a posse indígena com base no reconhecimento de direitos consuetudinários, herança do sistema jurídico britânico de tal direito imposto no período colonial. No Brasil, o sistema jurídico de direito civil segue a Constituição de 1988, que reconhece os direitos indígenas às suas terras como direitos originários.

As recentes transformações políticas no cenário internacional das relações entre, de um lado, os povos indígenas e, do outro, o Estado e a sociedade civil têm acontecido com certa rapidez no Brasil, sobretudo a partir da Constituição de 1988, com um processo crescente de concessão de poder aos povos indígenas. Além das mudanças na Constituição brasileira de 1988, o governo brasileiro reconhece a legislação internacional, como a Convenção n. ${ }^{\circ} 169$ sobre Povos Indígenas e Tribais em Países Independentes, aprovada pela Organização Internacional do Trabalho (OIT) em 7 de junho de 1989 e ratificada em 2002 pelo governo brasileiro, depois de tramitar por 11 anos no Congresso Nacional. Ao entrar em vigor em 27 de julho de 2003, a Convenção n. ${ }^{0} 169$ da OIT traz, para o ordenamento jurídico brasileiro, diversas inovações que contribuirão para a defesa dos povos indígenas, passando a ser um importante instrumento internacional na defesa dos direitos indígenas brasileiros. A adoção da palavra "povos", fundamentada no princípio de que os índios são sociedades permanentes, tem como intuito propiciar o estabelecimento de uma nova relação entre os indígenas e o Estado, baseada no reconhecimento da diversidade cultural e étnica. Além disso, a utilização do termo implica outorgar-lhes proteção e incentivá-los a estabelecer suas próprias prioridades de desenvolvimento. A Guiana ainda não ratificou a Convenção n. ${ }^{\circ} 169$ do OIT.

A partir da década de 70 do século XX, com o crescimento de movimentos indígenas, esses povos têm expressado sua etnicidade por meio da mobilização política em organizações indígenas, além de participarem de partidos po- líticos das sociedades nacionais. Enquanto no Brasil, a partir da década de 70, os povos indígenas do nordeste de Roraima têm-se organizado politicamente em instituições como o Conselho Indígena de Roraima (CIR), a Associação de Professores Indígenas de Roraima (APIRR), a Organização de Mulheres Indígenas de Roraima (OMIR), a Sociedade de Índios Unidos do Norte de Roraima (SODIUR), entre outras (Repetto, 2008), no lado guianense da fronteira, apesar da crescente influência de organizações políticas indígenas, sobretudo a Amerindian Peoples Association (APA), os povos indígenas têm uma longa história de participação nos partidos políticos daquele país.

Na Guiana, a organização não governamental indígena Amerindian Peoples Association (APA) (www.sdnp.org.gy/apa/), criada em 1991 e reconhecida desde 1992, tem ganhado força política em relação a direitos territoriais nessa região de fronteira, entre as quatro principais organizações indígenas no âmbito nacional. A APA realiza levantamento das terras indígenas em toda a região do Rupununi, visando a apresentar as reivindicações indígenas ao governo, para propor a sua demarcação em áreas contínuas, emendando as terras indígenas atualmente reconhecidas pelo governo guianense que estão, na sua maioria, divididas em áreas fragmentadas. A demarcação das terras indígenas em áreas contínuas é defendida pela maioria dos indígenas que mora em aldeias e depende da terra para sua subsistência, enquanto a maioria das populações urbanas, indígenas e não indígenas, apoia a demarcação em áreas fragmentadas.

No final de 1999, a Assembleia Nacional da Guiana aprovou várias emendas na Constituição da Guiana, inclusive no que diz respeito aos direitos de povos indígenas à proteção, à conservação e à promulgação de suas línguas, seu patrimônio cultural e modos de vida, emendas baseadas em recomendações da Constitution Reform Commission (CRC). Ao longo do ano de 1999, a APA realizou oficinas sobre reforma constitucional por toda a Guiana, com o intuito 
de preparar as recomendações para a CRC. As recomendações apresentadas à CRC pela APA incluíram um capítulo sobre direitos indígenas, que a Comissão não incluiu em suas recomendações encaminhadas à Assembleia Nacional. Apesar da exclusão desse capítulo, a APA considerou a inclusão de direitos básicos para a proteção e a conservação da cultura indígena um avanço importante. A Ata Indígena da Guiana foi promulgada em 1951, revisada em 1976 e novamente em 2004, sendo a principal legislação do governo guianense que trata de direitos indígenas. Em 2005, uma coalizão de organizações não governamentais indígenas - Amerindian Peoples Association (APA), The Amerindian Action Movement of Guyana (TAAMOG) e Guyana Organisation of Indigenous Peoples (GOIP) - rejeitou a última emenda à Ata Indígena como inaceitável, por representar um retrocesso quanto aos direitos dos povos indígenas na Guiana.

Para entender o contexto dessa fronteira internacional, é necessário resgatar a história da atuação dos dois países em relação a ela, tarefa já realizada por Paulo Santilli $(1994,2001)$ e por Nádia Farage (1991, 1997). Santilli afirma que, em 1927, a migração de índios do Brasil para a Guiana Inglesa, provocada por violências cometidas por fazendeiros brasileiros, ainda era uma preocupação para os estrategistas militares. Acrescenta Santilli (1994, p.68-69) que a "migração talvez não seja o termo mais exato para definir o processo", pois ele se caracteriza por deslocamentos dentro de um mesmo território tradicional, em que a fronteira internacional havia sido imposta.

Depoimentos recentes de moradores Makuxi e Wapichana, do lado guianense da fronteira, ressaltam esse fluxo populacional do Brasil para a Guiana, antes da sua independência em 1966, muitos com nomes portugueses e antepassados nascidos no Brasil. Atribuem a mudança para a Guiana à invasão do território indígena do lado brasileiro por pecuaristas e às invasões esporádicas por garimpeiros a partir das décadas de 20 e 30 do Século XX. Além disso, afirmam que, antes da independência da Guiana e da revolta do Rupununi em 1969, em que fazendeiros e seus trabalhadores indígenas, na região fronteiriça do Rupununi, declararam a independência da Guiana, os serviços de educação e de saúde oferecidos pelo governo colonial eram melhores na Guiana do que no Brasil, situação que se inverteu nos anos posteriores à revolta.

A independência da Guiana foi seguida de muitos conflitos políticos naquele país, especialmente entre os grupos étnicos majoritários de afro-guianenses e indo-guianenses no densamente povoado litoral. Na revolta do Rupununi, os Wapichana apoiaram os fazendeiros brancos e mestiços da região fronteiriça (Farage, 1997). Forbes Burnham, primeiro ministro (1964-1980) e presidente (1980-1985) da Guiana, representava a população afro-guianense. Após ter sido eleito, Forbes Burnham declarou a Guiana "República Cooperativista", em 1970, e aliou-se ao bloco soviético. Cabe mencionar que, após a divisão do People's Progressive Party em 1955, a política partidária, na Guiana, configurou-se mais em termos étnicos do que ideológicos. Os conflitos étnicos no densamente povoado litoral do país expressam-se na configuração dos partidos políticos. Os dois maiores partidos são o People's Progressive Party (PPP, fundado em 1950, que obteve, nas eleições de 2006, 54,6\% dos votos), visto como representante, sobretudo, dos indoguianenses, e o People's National Congress (PNC, fundado em 1955, que obteve, nas eleições de 2006, 34\% dos votos, dos afro-guianenses). Entre 1964 e 1992, o People's National Congress dominou o cenário político do país.

Os fazendeiros brancos e mestiços do Rupununi apoiavam The United Force (TUF), partido da direita fundado em 1960, e não se conformavam com o regime de Burnham. "Rebelaram-se os fazendeiros, incluindo a família Melville, cuja aliança histórica com os Wapichana pesou decididamente para obter seu apoio à revolta: na maioria das aldeias Wapishana, os homens aderiram à revolta." (Farage, 1997, p.55). A "Revolta do Rupununi” foi sufocada pelo exér- 
cito guianense, e muitos dos fazendeiros e seus trabalhadores wapichana exilaram-se na Venezuela e no Brasil.

\section{NACIONALIDADE E ETNICIDADE}

É quase unânime, entre os moradores da região do Rupununi (atualmente "Region 9, Upper Takutu-Upper Essequibo"), a decepção com a situação política na Guiana pós-independência e com o socialismo, por não terem sido superados os conflitos étnicos do país. Nas palavras de Clarindo Lucas, então vice-prefeito de Lethem, cidade fronteiriça da Guiana, à beira do rio Tacutu, em frente à cidade de Bonfim, Roraima, que se identifica como Wapichana de Aishalton: "Tanto o PPP quanto o PNC acreditam em ideologias socialistas. Todos pregam o marxismo e o leninismo, sobretudo o PNC. Então por que brigam? Não vejo nenhum sentido nisso". Sugeri que as brigas correspondessem a divisões étnicas, e Clarindo Lucas acrescentou que " $E$ isso mesmo. E isso vai existir para sempre".

Um ex-prefeito de Lethem, Muacir Baretto, morador de St. Ignatius, que se identifica como indígena, filho de pai Makuxi, casado com mulher Wapichana, descendente de brasileiros, mas de nacionalidade guianense, apresentou o Estado guianense como fraco e inviabilizado por conflitos entre os dois grupos étnicos majoritários de afro-guianenses e indo-guianenses. Identificou-se também como um ex-socialista que, na sua juventude, passou um ano como estudante em Moscou, no período soviético, e depois se decepcionou com o socialismo, ao ver que as tentativas de implantá-lo na Guiana levaram o país ao colapso econômico.

Muacir Baretto, numa entrevista em janeiro de 2004, afirmou que conhecia pessoalmente o presidente Forbes Burnham e trabalhou como coop officer no seu governo. Contudo admitiu haver cultivado resistência à política por ele implementada, mesmo antes de ir, em 1977, para a ex-União Soviética, onde passou dez me- ses. Orientado por uma cosmologia católica que entrava em choque com a ideologia marxista propagada pelo governo de Forbes Burnham, Muacir Baretto contou que se associou ao único partido capitalista da Guiana, The United Force (0,7\% dos votos nas eleições de 2001), o mesmo partido a que os fazendeiros dessa região e grande parte dos seus trabalhadores Wapichana aderiram na época da revolta do Rupununi em 1969. Muacir acrescentou sua decepção com o governo de Forbes Burnham pelo fato de o PNC conceder títulos por meio do Parlamento para apenas $25 \%$ das 24 a 25 mil milhas quadradas de terras indígenas. Contrariando o que o último Comissário de Terras havia recomendado após a independência, o PNC aprovou apenas 6 mil milhas quadradas na metade da década de 70 .

Ao mesmo tempo, a decepção com o governo da Guiana, dividido por conflitos étnicos, alia-se, na perspectiva de muitos habitantes dessa região de fronteira, à esperança no Brasil. Muitos dos entrevistados indígenas em Lethem e na aldeia vizinha de Santo Ignácio manifestaram a opinião de que os povos indígenas não têm nenhum futuro com o governo de Georgetown e olham para o Brasil, tomado como portador de grande sucesso econômico e como um caminho para escapar da pobreza acentuada e dos conflitos políticos e étnicos que assolam o densamente povoado litoral atlântico do país. $\mathrm{Na}$ sua etnografia sobre essa fronteira, Mariana Pereira observa também que "a identidade de brasileiro, no interior da sociedade guianense, em Lethem, desfruta de alto grau de prestígio, pois essa identidade está associada à imagem positiva e até utópica sobre o Brasil." (2005, p.157).

Na Guiana, a coalizão do Guyana Action Party (fundado em 1996) e do Working People's Alliance (fundado em 1979) - GAP-WPA $(2,4 \%$ dos votos nas eleições de 2001) - e a coalização do Guyana Action Party e do Rise Organise and Rebuild Guyana (1,2\% dos votos nas eleições de 2006) foi definida como "uma organização autônoma de povos indígenas". O fundador do GAP, o empresário Paul Hardy, é visto como mestiço, 
e a então parlamentar Shirley Melville apresenta-se como índia aruaque do litoral da Guiana. Embora esses políticos apelem para identidades indígenas, são vistos pela população local, em primeiro lugar, como empresários bem-sucedidos, e alguns informantes indígenas e não indígenas os identificaram como exploradores da mão de obra dos índios. Nesse contexto, as desigualdades regionais entre "índios" comerciantes citadinos e "índios" pobres, nas aldeias, sobrepujam qualquer identidade pan-indígena.

Os posicionamentos dos habitantes dessa região fronteiriça têm de ser considerados à luz das imensas desigualdades internacionais. A admiração pelo Brasil, como um país que "deu certo”, quando comparado com a situação econômica crítica da Guiana, não significa que essas pessoas defendam as imensas desigualdades, sobretudo no que diz respeito ao acesso à justiça, e uma ordem capitalista que se sustenta em relações de poder sistematicamente assimétricas. Ao não aceitar o socialismo da forma como se processaram as tentativas de efetivá-lo na Guiana, a maioria das pessoas entrevistadas no lado guianense dessa fronteira revelava uma preocupação quanto às injustiças sociais no Brasil. Muacir Baretto acrescentou que "Nós nos assustamos pela escalada de violência que está tendo no Brasil”.

A situação, nessa fronteira internacional, revela como as ideologias dos Estados permeiam o pensamento das populações indígenas, compreendidas nos contextos locais. Essas populações também estão estreitamente envolvidas em processos internacionais. Nos anos 2000, o filho de um ex-tuxaua de St. Ignatius fez um curso na China sobre miniusinas hidrelétricas (UHE) para trabalhar numa mini UHE implantada pelo governo chinês em Moko Moko, a poucos quilômetros de St. Ignatius. Outro jovem de St. Ignatius cursou medicina na Universidade de Cienfuegos, em Cuba, entre 2003 e 2009, com bolsa de estudos do governo cubano. Muitas das lideranças do Conselho Indígena de Roraima viajam frequentemente pelo mundo, participando de reuniões indígenas internacionais.
Os povos indígenas, tanto no lado brasileiro como no lado guianense dessa fronteira, enfatizam, com frequência, a distinção entre a população indígena urbana e a população indígena que mora nas aldeias. Muacir Baretto, em janeiro de 2005, afirmou:

Os índios que moram nas cidades como Lethem e Bonfim têm uma perspectiva bem diferente daquela dos índios que habitam as aldeias. Muitos habitantes de Bonfim têm criticado a homologação da Terra Indígena Raposa Serra do Sol em área contínua. Os índios que moram nas cidades, eles começam a pensar como os citadinos, e os citadinos não são índios. Então, quando eles têm de tomar partido, eles se identificam com as pessoas que estão contra a demarcação em área contínua. Pensam como os habitantes da cidade.

Tanto na Guiana como no Brasil, há divergências a respeito de quem é indígena. Uma exprefeita de Uiramutã passou a identificar-se como índia Makuxi - na época ligada ao PT - mas não era considerada índia pelo CIR, pois ela não era reconhecida como índia pela maioria das lideranças da Terra Indígena Raposa Serra do Sol. Ao tentar a reeleição, a ex-prefeita continuava lutando contra a homologação contínua dessa terra indígena e acusava o CIR de não a considerar índia por "preconceito", afirmando que "A partir do momento que me posicionei contra a homologação contínua da reserva Raposa/Serra do Sol, deixei de ser índia para as lideranças dos grupos contrários ao meu posicionamento." (Folha de São Paulo, 23/05/2004).

O crescimento econômico de Roraima iniciou-se após a criação do Território Federal de Roraima em 1944, e sua transformação em Estado, em janeiro de 1991, trouxe um aumento populacional extremamente rápido, com a vinda de migrantes de outras regiões do Brasil, especialmente para a capital Boa Vista. Como nunca antes na sua história, os territórios indígenas tornaram-se alvo de ocupação por pecuaristas, agroindustriais e garimpeiros a partir de 1990 , sobretudo com as operações de retirada de invasores da área indígena Yanomami (Santilli, 2001).

Nessa fronteira internacional, a reafirmação étnica como índios - Makuxi, Wapichana e outras 
etnias - acontece num contexto marcado por interesses políticos partidários em conflito aberto. Surgem diversas formas altamente politizadas de se identificar como índio, mestiço, Makuxi, Wapichana, brasileiro, guianense, ou Amerindian, além de identidades altamente pejorativas, como caboclo no Brasil e buckman (homem animalesco) na Guiana. Essas identidades muitas vezes se sobrepõem, parecendo, à primeira vista, contraditórias. Os conceitos de território são moldados em contextos altamente politizados, que refletem as divisões políticas nessa região. As flutuações econômicas internas nos dois países levaram a fluxos migratórios, e, com a crescente redução de recursos para políticas públicas por parte dos governos, as ONGs indígenas, indigenistas e ambientais, nacionais e transnacionais, passaram a desempenhar um papel predominante, com frequente sobreposição de interesses. Muitos dos moradores nessa fronteira são portadores de documentos de identidade da República Cooperativista da Guiana, com nome em inglês, e de documentos do Brasil com outro nome, em português, o que caracteriza o processo de transnacionalização apontado por Cardoso de Oliveira.

Em anos recentes, a crescente influência da Amerindian Peoples Association (APA), na Região 9 da Guiana, tem levado parte da população indígena a contestar as reduzidas demarcações de terras indígenas realizadas pelo governo guianense. A APA organizou equipes que estão efetivando um levantamento das terras indígenas reivindicadas pelos moradores de aldeias, para submeter propostas de redefinição dessas terras na base de direitos consuetudinários que nunca foram extintos durante o período colonial e na pós-independência, incluindo algumas propostas de regularização de áreas contínuas maiores, que reúnem diversas áreas demarcadas anteriormente em ilhas e atualmente cercadas por fazendas. A APA tem dialogado tanto com o Estado guianense quanto com outras ONGs ambientalistas internacionais, como a Conservation International, que atuam nessa região.

No lado brasileiro da fronteira, após uma luta política que durou trinta anos, a homologação, em 15 de abril de 2005, da Terra Indígena Raposa Serra do Sol, de acordo com a Constituição brasileira, em área contínua de 1.747.460 hectares, com uma população indígena estimada em 17.559 indivíduos (FUNAI, Boa Vista), contrasta com as demarcações de Terras Indígenas em pequenas áreas cercadas por fazendas na região da Serra da Lua, ao sul, onde a maioria das Terras Indígenas é de extensão reduzida para sustenta suas populações que estão em pleno crescimento. A demarcação fragmentada na Serra da Lua - região ocupada por fazendeiros antes da consolidação do movimento indígena em Roraima e consequente reivindicação dos seus direitos originários às suas terras - resultou em uma situação atual de frequentes conflitos entre fazendeiros e povos indígenas.

Os indígenas que habitam a Terra Indígena Raposa Serra do Sol exigem a garantia e a proteção integral de suas terras e dos recursos naturais, onde arrozeiros invasores continuaram, até o início de 2009, a explorar indevidamente as terras e os rios. Pressões por parte de políticos e empresários de Roraima tentaram reverter a demarcação e a homologação dessa Terra Indígena, para que fosse "julgada” novamente a sua legitimidade. Após três sessões, o Supremo Tribunal Federal (STF) manteve a decisão favorável à demarcação contínua da reserva indígena Raposa Serra do Sol, em Roraima, o que beneficia os povos indígenas e determina a saída dos fazendeiros da região. Em 19 de março de 2009, a decisão, por dez votos a um, dos ministros do STF derruba uma ação impetrada em 2005 por um senador de Roraima contra a criação da Terra Indígena de 1,7 milhão de hectares determinada pelo presidente Luiz Inácio Lula da Silva no mesmo ano. A demarcação foi aprovada com dezenove restrições, dezoito propostas por um dos ministros do STF em dezembro de 2008 e uma apresentada pelo presidente do STF em março de 2009.

Apesar de existirem redes de parentesco que se ramificam entre as aldeias nos dois lados dessa fronteira e por dentro desses dois Estados nacio- 
nais, por toda a região do lavrado, e fluxos de migrantes que, em anos recentes, têm vindo da Guiana para o Brasil, o diálogo que existe entre as principais organizações políticas indígenas, nessas regiões de fronteira, o CIR e a APA, é ainda incipiente. Entretanto, em cada um dos Estados nacionais, os movimentos políticos indígenas, por intermédio dessas organizações indígenas, seguindo os sistemas jurídicos dos seus respectivos Estados nacionais e os direitos internacionais dos povos indígenas, estão reivindicando a regularização de terras indígenas, para permitir a sobrevivência cultural dos povos autóctones que habitam essa região desde muito antes da imposição de uma fronteira internacional.

No Estado de Roraima, no Brasil, o movimento indígena tem reivindicado uma educação indígena diferenciada, que respeite a cultura e os saberes tradicionais de cada povo, direito garantido pela Constituição Federal Brasileira de 1988. Na Guiana, a tendência tem sido reivindicar a implantação, nas comunidades indígenas, de escolas e colégios da rede do sistema nacional de ensino, e, recentemente, a Amerindian Peoples Association (APA) tem reivindicado o direito a uma educação indígena diferenciada. Num quadro histórico de exclusão social, nos últimos anos, os Estados Nacionais e algumas organizações não governamentais têm formulado e implantado políticas de inclusão social, com a participação de antropólogos. O projeto político-pedagógico do Curso de Licenciatura Intercultural, do Núcleo Insikiran de Formação Superior Indígena da Universidade Federal de Roraima (desde 2009, Instituto) (Carvalho; Fernandes; Repetto, 2008), no Brasil, é uma iniciativa pioneira na educação superior federal brasileira. Desde sua implementação em meados de 2003, quando se iniciaram as atividades da Licenciatura Intercultural, o projeto tem sofrido revisões. A primeira seleção específica para o curso de Licenciatura Intercultural foi realizada em janeiro de 2003, e aulas tiveram início em julho do mesmo ano, com uma turma de 60 alunos. O objetivo principal é a formação de professores indígenas que possam contribuir para o benefício de suas comunidades. O curso foi criado com base em uma reivindicação e um diálogo entre setores da UFRR, instituições públicas e as organizações indígenas do Estado de Roraima. A discussão estendeu-se às comunidades indígenas, que participaram da definição da proposta. O curso de Licenciatura Intercultural tem duração de cinco anos: dois anos de formação comum e três anos de concentração. O objetivo é levar os professores indígenas a construir sua própria educação escolar.

O Instituto transformou-se em um centro de referência na formação indígena de nível superior e busca atender às reivindicações das comunidades e das organizações indígenas e às exigências legais do Ministério da Educação. O curso de Licenciatura Intercultural do Instituto Insikiran visa à construção de uma universidade mais justa, que permita a inclusão social dos povos indígenas, respeitando suas diferenças culturais. ${ }^{2}$ O Instituto Insikiran faz parte de um esforço feito pelos povos indígenas, ao longo da última década, no sentido de profissionalizar os quadros das suas organizações e lideranças (Luciano, 2006). Mesmo que haja um mesmo esforço na Guiana, conforme informações divulgadas pela APA, apenas $0,1 \%$ da população das áreas rurais tem acesso à educação superior. A APA coordena programas de capacitação para as comunidades indígenas, inclusive programas sobre direitos indígenas.

Enquanto os governos dos respectivos países têm implementado políticas de educação e saúde, continua a pressão por parte de empresários e políticos de Roraima para implantar projetos desenvolvimentistas regionais de mineração e agropecuária nas Terras Indígenas. Apesar da rati-

${ }^{2}$ Outra licenciatura indígena foi estabelecida na Universidade do Estado de Mato Grosso - UNEMAT- em seu campus de Barra dos Bugres, e várias universidades estão abrindo cotas de vagas para alunos indígenas e negros, com o objetivo de tentar reverter uma longa história de exclusão dessas populações. Atualmente o Brasil tem 1044 professores indígenas fazendo licenciatura específica em nove universidades federais e estaduais em todo o país. E há atualmente mais de 6000 indígenas cursando o ensino superior no Brasil, conforme nos informou Gersem Luciano Baniwa, coordenador do Centro Indígena de Estudos e Pesquisas (CINEP) em 20 de abril de 2009. 
ficação da demarcação e da homologação da Terra Indígena Raposa Serra do Sol em 2009 pelo STF, os interesses desenvolvimentistas continuam a procurar novas estratégias para tentar apoderar-se dos recursos naturais em Terras Indígenas.

\section{CONCLUSÃO}

No início deste trabalho, citamos um trecho de um texto de Cardoso de Oliveira, no qual, ao abordar a questão dos povos indígenas que vivem em fronteiras internacionais, o autor refere-se à "manipulação de identidade junto a representantes dos respectivos Estados nacionais" (Oliveira, 2000, p.17) em situações como a procura de assistência à saúde, educação dos filhos, etc. Como afirmamos ao longo deste trabalho, a contextualização de identidades pelos indígenas que vivem na fronteira, apesar de parecer contraditória e ambígua - na perspectiva hegemônica do Estado nacional que pensa a nacionalidade como uma identidade exclusiva -, não é concebida dessa maneira pelos indígenas, que não veem contradição alguma no fato de se identificarem como brasileiros e guianenses. Muitos são portadores de documentos de ambos os países. Quase todos têm parentes que vivem nos dois lados da fronteira. Não veem nenhuma ambiguidade em identificar-se conforme os contextos em que estão inseridos e que lhes parecem naturais. Tampouco veem nenhuma contradição em identificar-se como Makuxi e Wapichana, e mesmo por outras identidades étnicas, ao terem familiares de mais de uma etnia em aldeias que atualmente são multiétnicas, além de serem transnacionais. Então, a afirmação de uma identidade nacional não seria uma manipulação de identidade do ponto de vista desses indígenas.

Propomos o uso da noção de "identidades contextualizadas", conforme se assuma ora uma, ora outra nacionalidade, sabendo-se que, frequentemente, ambas as nacionalidades e duas ou mais identidades étnicas são assumidas simultaneamente. Embora os indígenas que vivem nessa fronteira pertençam a redes de parentesco que se estendem dos dois lados da fronteira para o interior desses países e muito além, e apesar de haver um fluxo de pessoas que transita constantemente pela fronteira, a presença dos Estados nacionais com políticas indigenistas e culturas muito diferentes criou uma situação em que os indígenas veem essas políticas como parte de dois mundos distintos, havendo poucas interações entre suas respectivas organizações indígenas. Na perspectiva dos indígenas que vivem na fronteira, o que se destaca são as contradições e as ambiguidades dos discursos governamentais dos respectivos Estados nacionais a respeito de nacionalidade e etnicidade.

(Recebido para publicação em 15 de novembro de 2011) (Aceito em 22 de fevereiro de 2012)

\section{REFERÊNCIAS}

BAINES, S. G. A fronteira Brasil-Guiana e os povos indígenas. Revista de Estudos e Pesquisas Brasília, DF, Fundação Nacional do Índio, v.1, n.1, p.65-98, 2004.

CARVALHO, F. A.; FERNANDES, M. L.; REPETTO, M. (Org.) Projeto político-pedagógico do Curso de Licenciatura Intercultural. Boa Vista: Ed. da UFRR, 2008.

FARAGE, N. As muralhas dos sertões: os povos indígenas no rio Branco e a colonização. Rio de Janeiro: Paz e Terra; ANPOCS, 1991

As flores da fala: práticas retóricas entre os Wapishana. 1997. 298 f. Tese (Doutorado em Letras) - Departamento de Letras Clássicas e Vernáculas, Faculdade de Filosofia, Letras e Ciências Humanas da USP. São Paulo, 1997.

FOLHA DE SÃO PAULO, 23 de maio de 2004

LUCIANO, G. J. dos S. O índio brasileiro: o que você precisa saber sobre os povos indígenas no Brasil de hoje. Brasília DF: MEC/SECAD; Rio de Janeiro: LACED/Museu Nacional, 2006 (Coleção Educação para Todos, Série Vias dos saberes, n.1).

OLIVEIRA, R. C. de. Os (des)caminhos da identidade. Revista Brasileira de Ciências Sociais, São Paulo, v.15, n.42, p.7-21, 2000.

Introdução. In: BAINES, S. G. (Org.) Nacionalidade e etnicidade em fronteiras. Brasília, DF: UnB, 2005. p.9-20. ras. Brasília, DF: UnB, 2005.

Nacionalidade e etnicidade em frontei-

PEREIRA, M. C. A ponte imaginária: o trânsito de etnias na fronteira Brasil-Guiana. 2005. Tese (Doutorado em Antropologia) - Centro de Pesquisa e Pós-Graduação sobre as Américas, UnB. Brasília, DF, 2005. 
RAMOS, A. R. A antropologia brasileira no mundo. In: SANTILLI, P. Fronteiras da República: história e política RIBEIRO, G. L. et al. (Org.) As Ciências Sociais no mundo entre os Macuxi no vale do rio Branco. São Paulo: NHIIcontemporâneo. Brasília, DF: LetrasLivres; UnB, 2011. p. USP; FAPESP, 1994.

17-32.

Pemongon Patá: território Macuxi, rotas de conREPETTO, M. Movimentos indígenas e conflitos territoriais flito. São Paulo: Ed. da UNESP, 2001. no Estado de Roraima. Boa Vista: Ed. UFRR, 2008.

RIVIÈRE, P. Absent-minded imperialism: Britain and the expansion of empire in nineteenth-century Brazil. London: Tauris Academic Studies, 1995. 


\section{THE INDIGENOUS POLITICAL MOVEMENT IN RORAIMA: indigenous and national identities in the border of Brazil and Guiana}

\author{
Stephen G. Baines
}

This article discusses the indigenous political movement which has been consolidated in Roraima State, Brazil, since the 1970s, through the strengthening of indigenous identities, focusing above all on the Macushi and Wapishana. An analysis is made of the interface of these identities with Brazilian and Guyanese national identities, on the international border, which became clearly defined after this border was demarcated in 1904 The ways in which these identities overlap, and exist together simultaneously as contextualised identities is examined among the indigenous peoples who inhabit this region since long before the international border was imposed.

KEy-WORDS: indigenous movement, Makuxi, Wapichana, ethnical and national identities, frontier.

\section{LE MOUVEMENT POLITIQUE INDIGÈNE À RORAIMA: identités indigènes et nationales à la frontière du Brésil et de La Guyanne}

\author{
Stephen G. Baines
}

Ce travail traite du mouvement politique indigène qui s'est consolidé à partir des années 70 du XXe siècle, dans l'État de Roraima, grâce au renforcement des identités autochtones, et en prenant tout spécialement en considération les Makuxi et les Wapichana. Une analyse est faite de l'interface de ces identités avec les identités nationales brésilienne et guyannaise, à la frontière internationale, qui se sont consolidées à partir de la définition de cette frontière en 1904. On analyse la manière dont ces identités se supperposent et on cherche à savoir si elles se cotoient comme des identités en contexte avec les peuples autochtones qui habitent cette région depuis bien avant l'imposition des frontières internationales

Mots-CLÉs: mouvement indigène, Makuxi, Wapichana, identités nationales et ethniques, frontière.

Stephen Grant Baines - Doutor em Antropologia. Professor Associado da Universidade de Brasília. Pesquisador 1 do CNPq. Publicou 65 artigos em periódicos especializados e 71 trabalhos em anais de eventos. Possui 24 capítulos de livros e um livro publicado e quatro livros co-organizados. Participa de quatro projetos de pesquisa. Atua na área de Antropologia, com ênfase em Etnologia Indígena. Em seu currículo Lattes os termos mais frequentes na contextualização da produção científica, tecnológica e artístico-cultural são: Brasil, Waimiri-Atroari, os impactos de grandes projetos de desenvolvimento (mineração industrial e Usinas Hidrelétricas) em povos indígenas, etnicidade, índios, fronteira, Politica Indigenista, indigenismo, nacionalidade, Estilos de Antropologia e Indios. Além de haver realizado pesquisa etnográficas com os Waimiri-Atroari (1982-1985) e atualmente com os Makuxi e os Wapichana na fronteira Brasil-Guiana. Vem acompanhando a situação dos Tremembé no litoral do Ceará desde 2000, e a partir de janeiro de 2008, está participando do projeto de pesquisa “Criminalização e Situação Prisional de Índios no Brasil” (ABA/ESMPU) no qual coordena a pesquisa sobre "Situação Prisional de Índios em Roraima”. Foi co-coordenador do projeto do Professor Roberto Cardoso de Oliveira sobre fronteiras internacionais. É Coordenador do Projeto de Pesquisa no CNPq, "Etnologia Indígena em Contextos Nacionais: Brasil - Austrália - Canadá (com pesquisas etnográficas)". E credenciado para dar aulas e orientar alunos de doutorado e mestrado no Centro de Pesquisa e PósGraduação sobre as Américas - CEPPAC, UnB. 